\title{
Maintenance as a Guarantee for Roofing Performance in Buildings with Heritage Value
}

\author{
Patrícia Fernandes Rocha * and Rui Calejo Rodrigues \\ Civil Engineering Department, University of Porto, 4200-465 Porto, Portugal; calejo@fe.up.pt \\ * Correspondence: dec10002@fe.up.pt; Tel.: +351-220-413-799 \\ Academic Editor: Kheir Al-Kodmany \\ Received: 7 January 2016; Accepted: 30 March 2016; Published: 2 April 2016
}

\begin{abstract}
This paper is the result of the research conducted at the University of Porto and follows up on the Ph.D. thesis developed by the second author, which deals with the issue of the non-inclusion of maintenance at the time of architectural design, and of support instruments for the project author to help him in this endeavor. This work is intended to apply a guiding methodology to the design process that includes building maintenance benchmarked by the service behavior with regard to pitched roofs. The development of a decision support model enabled to obtain a maintainability index (MI) to be identified and results from the combination of two indicators: the importance indicator (Iid) and the easiness indicator (Eid). The results achieved enable the project author to have a support tool for making decisions that affect the building behavior in service as well the act of the preservation of heritage value.
\end{abstract}

Keywords: architectural design; building maintenance; decision support system (DSS); service behavior; functional performance.

\section{Introduction}

The issue of maintenance has not yet been debated to the extent that its true scale warrants. The growing deterioration of buildings and their loss of functionality is a continuing challenge, and this arises, more often than not, out of a lack of maintenance of the existing building stock. The concept of building maintenance, like most concepts, has undergone changes over time since the first standard, BS 3811 [1] in 1984, and may be defined today as the "combination of all technical and administrative actions carried out on a building in order to maintain or restore its elements and components to a condition in which it can perform the functions it was designed for" [2].

On the one hand, maintenance has been increasingly considered as an area of knowledge that contributes to ensuring the buildings behavior in service. On the other hand, societies, because of the way in which they often regard architectural issues, presume that the construction of a building is such that it "should last forever". The truth is that every building has a variable life cycle that inevitably expires. Today, one of the problems is precisely not knowing with any degree of accuracy the future performance of many construction materials and techniques, whereas maintenance must be one of the factors that enables predefined requirements to be ensured and helps guarantee their future in-service behavior under normal conditions. The importance of including maintenance concerns from the earliest design stages must, therefore, be envisaged.

The definition of methods sustained by support methodologies, also in building rehabilitation and structuring during the design process, was addressed by Roders [3], who sought to define a support system for design methodology for architects and, simultaneously, to understand what built heritage (object) is in reality, how rehabilitation (action) should be carried out, and with what design process, technologies, and materials (tools) should be undertaken. 
The method developed aims to build a support tool for the designer during the design process so that choosing a given solution may identify its implications for maintenance, and is applied to pitched roofs.

\section{Intervention Strategies on Existing Buildings}

In societies, architecture has a duty to preserve the past and provide the possibility of building the present on the strength of culture and tradition. We do not live only in a material and spatial reality, but also inhabit cultural, social, and temporal realities. Architecture is essentially a way to reconcile and identify since it gives meaning to things and, moreover, situates the human being in space and a place between the past and the future. Moreover, there is a sense of permanence associated with it. In terms of the design process, this permanence is achieved, on the one hand, through an effective liaison between all the stakeholders in the construction process and, on the other, through the definition of the set of requirements and actions which it must meet, finding technical and constructive solutions to guarantee the intended general performance.

Various studies have been undertaken on the main causes for anomalies in buildings. One of these was presented by Chamoza \& Ortiz [4], and, later on, the Centre Scientifique et Technique de la Construction (CSTC) study deserves a mention [5]. What should be retained, however, is that both studies point out design and execution errors or failures as the main anomalies in construction. Regardless of the factors that may interfere in the assessment of the maintenance indicators for the built architectural space, potential errors or failures during the design stages may be catalysts for maintenance and, in this case, have a leverage effect on a faster degradation [6].

With all these reflections, a further issue must be considered, that concerns the need to manage all of this existing heritage by ensuring its expected behavior. For this, a number of operational performance requirements need to be kept in mind, which should be met by the various parts of the building, as well as the fact that it will be subject to a number of possible anomalies throughout its service life. Their limitation and, to a certain extent, their prevention are possible by defining a Maintenance Plan that should be applied throughout its service life. It is also true that many of the solutions designed can be defined, bearing in mind that some of these manifestations, which could speed up the deterioration process, can be analyzed and somehow foreseen during the design process; i.e., to a certain extent, its future degradation process can be anticipated.

In the context of roofing, and with the model being applied to specific case studies in the city of Porto, the relevance of their application is consensual, since this element requiring maintenance is particularly responsible for a wide number of anomalies that, directly or indirectly, will emerge in buildings, as Figure 1 shows:

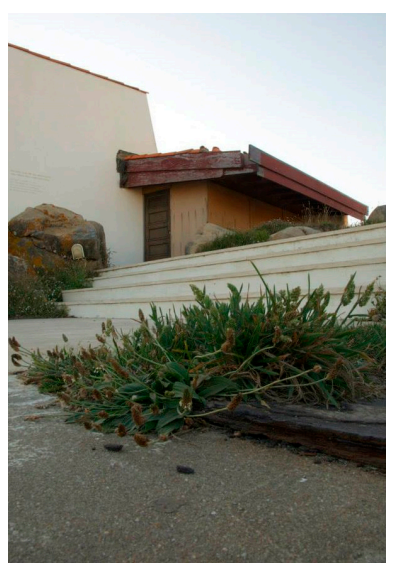

(a)

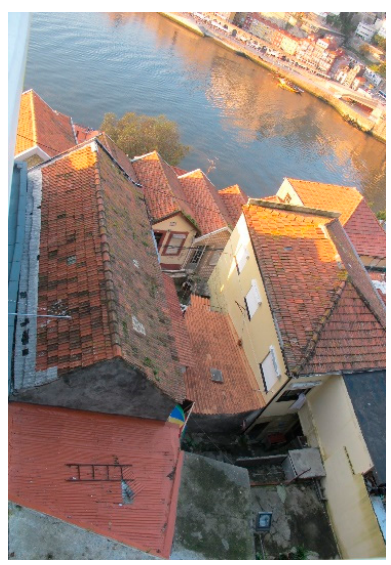

(b)

Figure 1. (a) Photograph of the Boa Nova Tea House by Architect Siza Vieira; (b) Photograph of the Historic Center of Porto. 
Rehabilitation should be regarded as an opportunity for evaluation in which the need is considered for carrying out a number of operations to make a building operational again, according to current standards. It is, therefore, an act that encompasses all the actions intended to ensure the knowledge of the building's characteristics and the study of the operational and constructive anomalies that affect it, including all the decisions resulting from the purposes behind the act of rehabilitation. Nonetheless, the maintenance issue must be associated with the rehabilitation solutions, even though the act of rehabilitation is often deprived of the required reasoning for the in-service performance of the solutions.

\section{Decision Support Model: Variables and Criteria}

\subsection{Definition of Decision Support Indicators}

The methodology developed in this work to support the model was based on the prior analysis of a number of buildings in the Historic Center of Porto, which were visited and observed in the course of the research, as a way of validating a set of both existing solutions and intervention solutions, and to identify the main constructive anomalies observed. This field work enabled a modus operandi to be defined in view of the reality observed to serve as a support in the identification and description of the main anomalies and solutions.

The decision variables were established on the principle that every architectural object must respond to a number of requirements and its conditions. These requirements must be ensured in the design process, as well as during its service behavior. Therefore, there's a set of maintenance procedures that must be established throughout the service life that guarantee this behavior. This is the main reasoning behind the model, by establishing the way in which maintenance procedures contribute to retaining the performance of the various requirements and conditions over time and under normal conditions.

In building maintenance, it is important to emphasize that the success of any maintenance strategy requires accurate identification of the main operations and procedures. The various procedures cannot be dissociated from a number of aspects related to building management and, more specifically, to their technical activity. Maintenance operations and their procedures are, in practice, the materialization of the activities that will ensure the service life of the various elements and components of a building.

They are defined from a broad set of maintenance operations, eight of which are regarded as key to the design process: Inspection, Pro-action, Cleaning, Sustainability, Correction, Replacement, Legal Enforcement and Conditions of Use. The intention is to assess the impact of each variable (action or alternative) against the criteria: the requirements (safety, comfort, adequacy, durability and economy) and conditions of operational performance that the design must meet, and the above-mentioned operations. In order to ensure the behavior of these requirements over time, certain relevant indicators certain indicators were considered: the importance indicator (Iid) and easiness indicator (Eid). The indicators can be explained as follows [7]:

- Importance indicator (Iid) — the evaluation of the importance of a maintenance process to ensure a certain operational performance requirement and its conditions;

- Easiness indicator (Eid) - the evaluation of how easy maintenance procedures/actions are for each process, for any given constructive solution for an elements source of maintenance (ESM).

The method found to evaluate the criterion (Iid) is defined in Table 1 below:

The values assigned were predefined through an audit supported by consultation with a wide range of architects by means of interviews and questionnaires. The method found to evaluate the criterion (Eid) is defined in Table 2 below: 
Table 1. Evaluation of the importance indicator (Iid).

\begin{tabular}{ccl}
\hline Weighting (\%) & \multicolumn{1}{c}{ Appraisal } & \multicolumn{1}{c}{ Description } \\
\hline$[0 ; 20]$ & No importance & $\begin{array}{l}\text { The maintenance operation has very little influence on ensuring the } \\
\text { operational performance requirement. } \\
\text { The maintenance operation has little influence on ensuring the operational } \\
\text { performance requirement. } \\
\text { The maintenance operation has a moderate influence on ensuring the } \\
\text { operational performance requirement. } \\
\text { The maintenance operation has a high influence on ensuring the } \\
\text { operational performance requirement. } \\
\text { The maintenance operation has a very high influence on ensuring the } \\
\text { operational performance requirement. }\end{array}$ \\
\hline [60;80] & Limited importance & High importance
\end{tabular}

Table 2. Evaluation of the easiness indicator (Eid).

\begin{tabular}{ccc}
\hline Weighting (\%) & Appraisal & Description \\
\hline$[0 ; 20]$ & No facility of maintenance & The maintenance operation require considerable additional effort. \\
] $20 ; 40]$ & Little facility of maintenance & The maintenance operation require some additional effort. \\
] $40 ; 60]$ & Moderate facility of maintenance & The maintenance operation require little additional effort. \\
$160 ; 80]$ & High facility of maintenance & The maintenance operation require very little additional effort. \\
] $80 ; 100]$ & Very high facility of maintenance & The maintenance operation require no additional effort. \\
\hline
\end{tabular}

The Eid values are assigned by defining a weight comprising a percentage of the value established on the basis of a guideline, which was defined by several assessment parameters of the solution, relating the various maintenance operations and procedures/actions to their feasibility as against that same solution.

The weighting of each evaluation parameter is assigned according to partial or full compliance and non-compliance because of impossibility, because there is no way to ensure the parameter, or because it has not been anticipated. Once the designer is unable to define the preceding parameter in order to proceed to the next ones, the weighting value is assigned (\%), thus defining the easiness of the solution in ensuring each maintenance operation. By way of example, Table 3 shows the various guidelines for obtaining the maintenance operation values for inspection:

Table 3. Guidelines to define the Eid weighting for inspection.

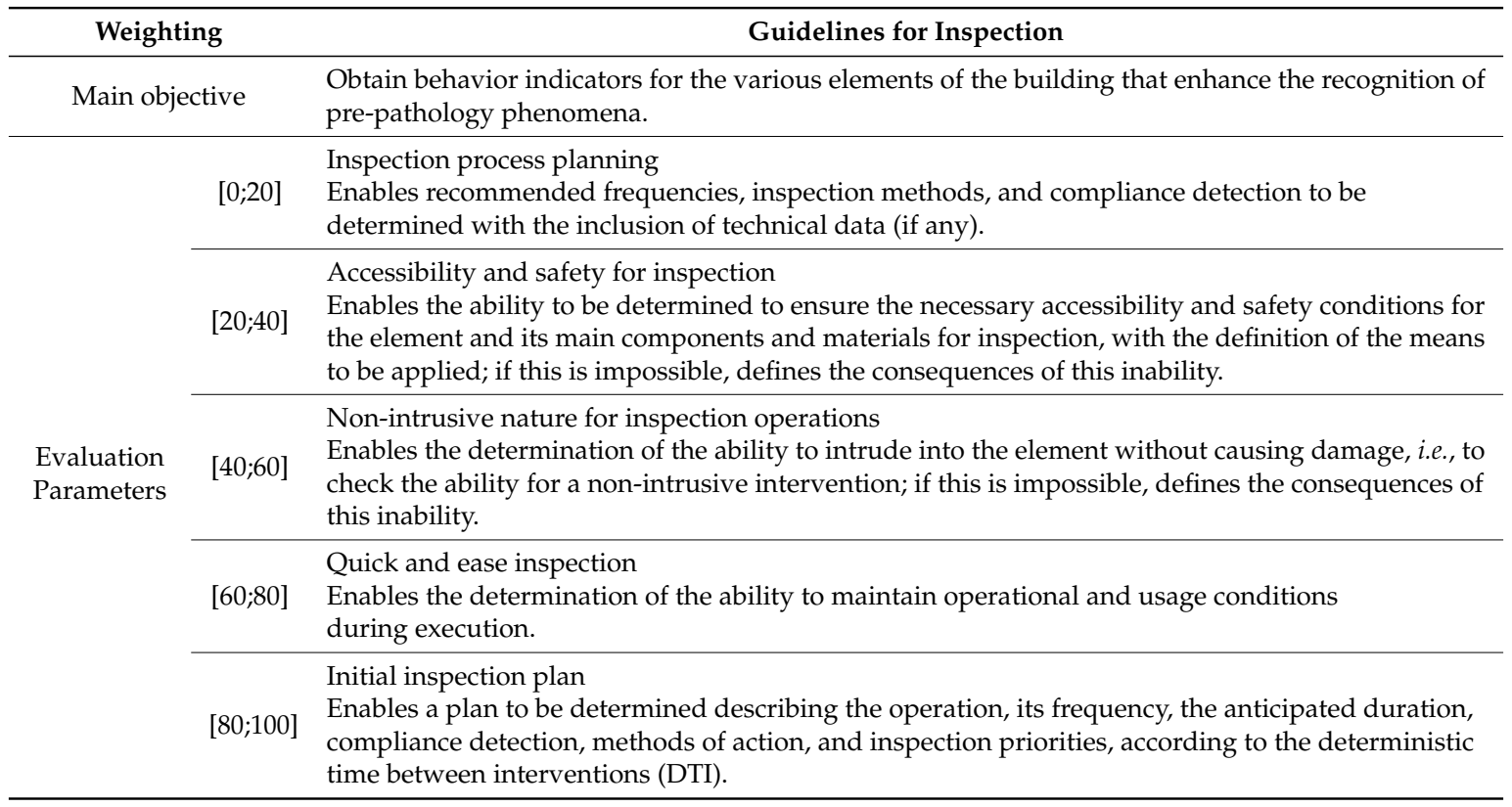




\subsection{Assignment of the Maintainability Index for Decision Support}

This index is the final output of the model which allows an initial Maintenance Plan to be defined for the various maintenance operations. Once the design and construction stages are completed, it should be updated and included in the Maintenance Plan to be implemented throughout the service life of the building in question [7].

To calculate the value for each index, an informatic support tool was developed. The referenced eight maintenance operations were addressed, and, after conversion, a map and associated polygonal and radar charts could be obtained. The only value introduced in the program by the project author is the Eid, by the compliance of each evaluation parameter of each maintenance operation. A more detailed explanation has been expressed in the Ph.D. thesis [7].

This index, to be assigned for each constructive solution and for each ESM, determines the readiness of a solution to perform maintenance operations. It is, therefore, the combined weighting of the two indicators and allows for a double reading, obtaining information on the importance of each maintenance operation to ensure each requirement and determine the easiness of performing a given maintenance operation. Table 4 shows the index evaluation method:

Table 4. Evaluation of the maintainability index (MI).

\begin{tabular}{ccc}
\hline Designation & Appraisal & Description \\
\hline $\operatorname{Im} 0$ & Insufficient & No readiness to perform maintenance operations. \\
$\operatorname{Im} 1$ & Very poor & Very little readiness to perform maintenance operations. \\
$\operatorname{Im} 2$ & Poor & Little readiness to perform maintenance operations. \\
$\operatorname{Im} 3$ & Sufficient & Reasonable readiness to perform maintenance operations. \\
$\operatorname{Im} 4$ & Good & Good readiness to perform maintenance operations. \\
$\operatorname{Im} 5$ & Very good & Very good readiness to perform maintenance operations. \\
\hline
\end{tabular}

This final appraisal in a qualitative scale is intended to be an aid to the designer in the decision act, so that he or she may consciously and intentionally decide on the constructive solution that best matches the design and by bearing maintenance in mind as part of this approach from early on.

Table 5 shows a summary of the main assumptions and aspects that allowed the proposed decision support model to be structured and modeled:

Table 5. Model summary table.

\begin{tabular}{|c|c|}
\hline Model Validation & Description \\
\hline Scope & Residential buildings. \\
\hline Aim & $\begin{array}{l}\text { To define a support tool for the designer as an aid in the design process to choose a solution } \\
\text { encompassing the relevant implications for maintenance. }\end{array}$ \\
\hline Breakdown & $\begin{array}{l}\text { Operational performance: } 5 \text { requirements and } 41 \text { topics } \\
\text { Maintenance processes: } 8 \text { operations }\end{array}$ \\
\hline Evaluation method & $\begin{array}{l}\text { Audit with interview and questionnaire; Applicable regulation inquiry and Available technical } \\
\text { data; Definition of Importance and Easiness Indicators. }\end{array}$ \\
\hline Evaluation criteria & $\begin{array}{l}\text { Importance Indicator [0;100] } \\
\text { Easiness Indicator [0;100] }\end{array}$ \\
\hline Weightings & $\begin{array}{l}\text { Importance Indicator-Evaluate the importance of each maintenance operation and procedure } \\
\text { to ensure operational performance (requirements and conditions). } \\
\text { Easiness Indicator-Evaluate how easy maintenance procedures and actions are for each } \\
\text { operation and for each constructive solution. }\end{array}$ \\
\hline Calculation methods & Total intermediate grades with polynomial, non-linear conversion and final weighted average. \\
\hline Final result & $\begin{array}{l}\text { Maintainability Index ]0;5[ } \\
\text { Polygon and Density Chart; Maintainability Sheet (document with data for the initial } \\
\text { maintenance plan) }\end{array}$ \\
\hline
\end{tabular}




\section{Discussion: Application of Model to the Element Requiring Maintenance-Roofing}

In middle-class residential buildings of Porto, the timber roof structure usually comprises a simple two-beam or rafter frame, laid out in a scissor shape and resting on another cross-beam or line which, in turn, rests on the party walls (Figure 2).

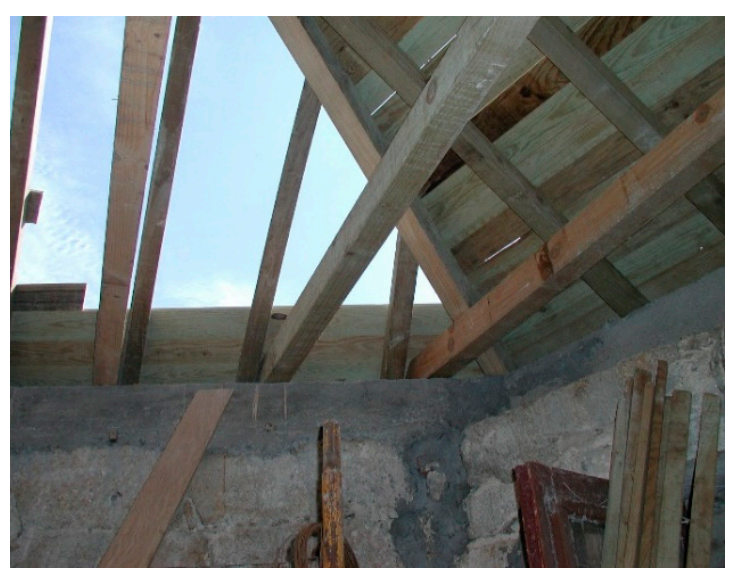

(a)

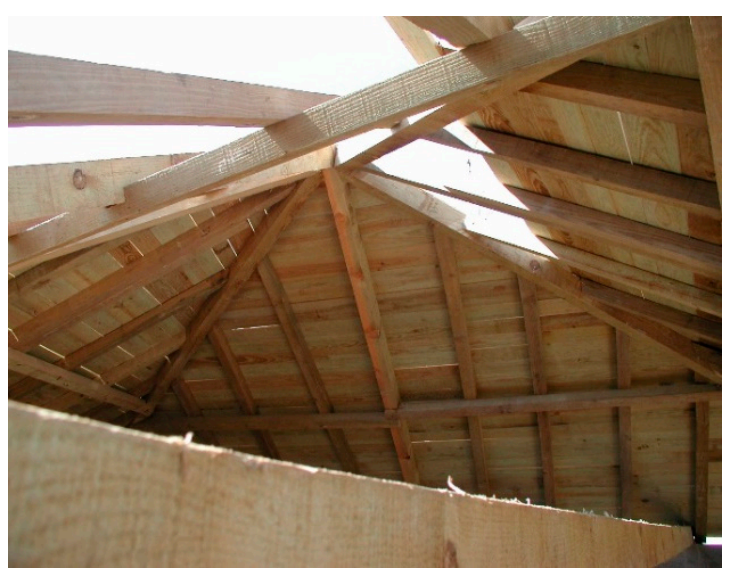

(b)

Figure 2. $(\mathbf{a}, \mathbf{b})$ Photograph of the hipped roof resting on party walls in Historic Center of Porto.

The roof is continually subject to external phenomena, such as the action of rain, wind, and biological agents, such as wood borers, dry rot, etc. It can be considered to be subject to the appearance of a considerable number of anomalies. In general, anomalies in timber structures could mean possible deterioration and excessive deformation.

In the case of timber deterioration, one of the main causes to be taken into account may be considered the lack of or insufficient protection of the various elements against degrading agents, especially dampness. If such dampness is a continuous factor, it may give rise to infiltration, which usually becomes evident through deficiencies in the support structure, dysfunction of the rainwater drainage network, or cladding anomalies. In the case of deficiencies in the support structure, excessive timber deformation (usually due to design errors) may account for adaptation movements of the whole system. This timber deficiency causes failures in its characteristics, notably through the loss of section or the degradation of strength and deformation capacity of the material itself. The potential rotting of timber structures usually occurs at the beam supports through dampness on the walls, impairing the overall consolidation of the building.

After an analysis of the various existing solutions and the identification of the main pre-existing anomalies, a number of intervention solutions is defined which are regarded as more current, either to retain the existing solution or to change it. As an example, was consider the SIF2 (code for each final intervention solution) solution-repair and reinforcement with epoxy products (Figure 3)—whose construction solution can be described as follows: 


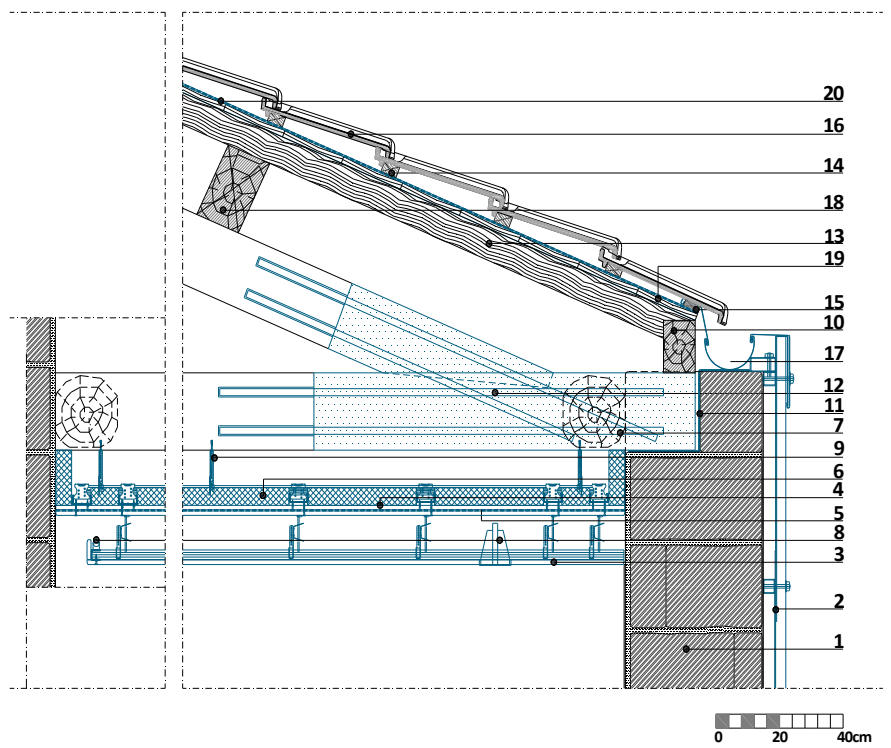

Figure 3. SIF2-intervention solution. 1. stone masonry wall; 2. galvanized steel plate; 3 . decorative suspended ceiling to be defined; 4. type A, STD, or H $12.5 \mathrm{~mm}$ thick double plasterboard panel; 5. top surface elastomer membrane at $3 \mathrm{~kg} / \mathrm{m}^{2} ; 6$. mineral wool panel with $70 \mathrm{~kg} / \mathrm{m}^{3}$ density; 7. beam for support of the roof structure; 8 . lighting (built into the panel or hidden in cove); 9 . metal kingpost; 10. Transom; 11. application of waterproofing coating, e.g., polymer-based bituminous course; 12. repair and reinforcement with fiberglass- or polyester- or epoxy resin paste-type epoxy products and embedded stainless steel bars; 13. rod or rafter; 14. Batten; 15. eaves beam; 16. Marseilles tile; 17. zinc gutter and flashing; 18. purlin (box section); 19. wooden lining; 20. water vapor flexible membrane (eventually).

The implementation of the model for the ESM, in this case, the roofing, initially covers the application of a calculation map, whose values for the Eid are the only cell to be filled in by the decision-maker. The values are obtained according to a guideline based on technical and practical considerations on the technologies under analysis, i.e., an audit, by reference to various literature sources and the experience factor (Table 6).

Table 6. Summary of the Eids introduced into the calculation map and the final result through the MI.

\begin{tabular}{ccc}
\hline Maintenance Operations & Easiness Indicator & Maintainability Index \\
\hline Inspection & 50 & 3 \\
Pro-action & 30 & 3 \\
Cleaning & 30 & 2 \\
Sustainability & 50 & 3 \\
Correction & 50 & 3 \\
Replacement & 30 & 2 \\
Legal enforcement & 50 & 3 \\
Conditions of use & 50 & 3 \\
\hline
\end{tabular}

After all calculations have been made and the final results have been shown through the assignment of an index to each maintenance operation, the results are represented by the polygon and density charts [7], as shown in Figure 4. 

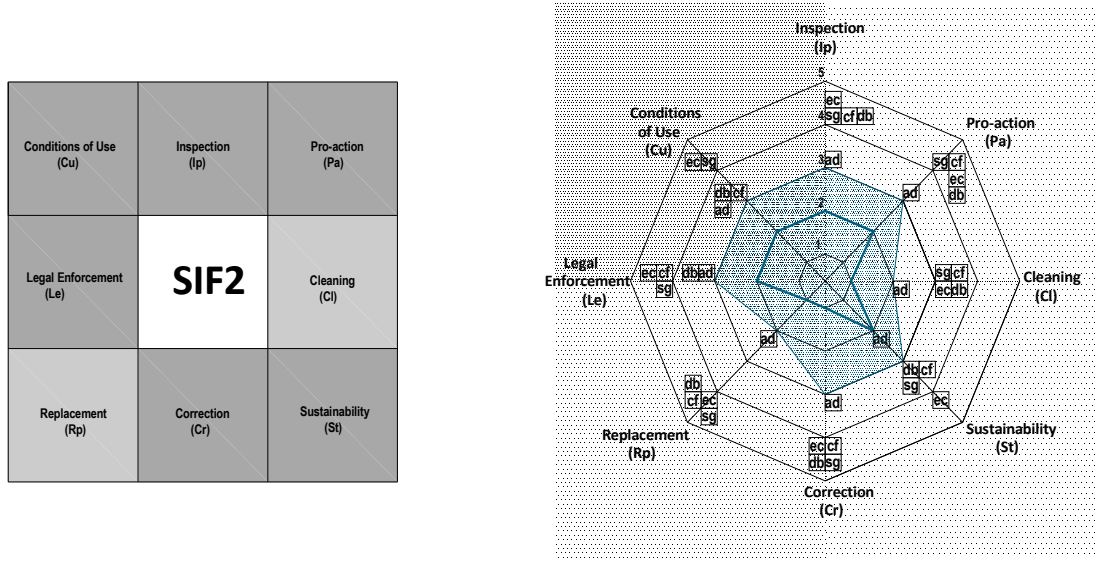

Figure 4. Final presentation of results.

From an analysis of the direct result of the model, it is possible to make maintenance recommendations for the solutions of the constructive system's element under analysis, in this case, the roofing. Here are some examples:

Inspection operation: Carry out an inspection to check the epoxy reinforcement and any deformations or sundry symptoms related to frequent or continuing dampness, especially in the supports, namely, texture unevenness, color changes, water content, presence of stains, infiltration, mould, and, through analysis of the timber, prostheses and rafter-wall connections, since this option increases the rigidity of ties, altering the rigidity distribution on the structure and the connections between the elements. (Resources: measurement of dampness, camera, amongst others; demands specialist assistance).

Pro-action operation: Evaluate the need for protective treatments (with an application of paint-based protection against ageing, fungi, insects, and termites) and treatment of structural changes using drying and fire protection methods. (Resources: use of products according to requirements, usually with the help of a brush, spray, or injection, among others; demands specialist assistance).

Cleaning operation: Remove accumulated sand, litter and leaves, fungi, moss and other debris from tiles and down pipes, gutters, and other drain components by means of cleaning operations comprising the elimination of salts, micro-organisms, and other particles. (Resources: pressurized water, broom, scraper, among others; Demands specialist assistance).

Correction operation: Check for broken and loose tiles and repair them by replacing tiles and support battens as required. (Demands specialist assistance; it may be necessary to remove tiles completely, clean them, and put them back).

Replacement operation: There is a possible future need for replacing a full load-bearing rafter. The likelihood of corrosion, even when using epoxy products for the protection of reinforcement, may cause damage over time which may require its replacement. (Demands specialist assistance).

Sustainability operation: Evaluate the consequences in the event that some maintenance operations are required, especially if rafters need to be replaced. Epoxy products may cause some problems due to loss of the original joinery since the bar works as a connection. Corrosion, even when using protective products, may cause irreversible damage over time because resin is very hard to remove.

Legal enforcement operation: Consolidation with epoxy products is possible since a fireproof suspended ceiling was installed. Epoxy resins lose strength for temperatures around $100{ }^{\circ} \mathrm{C}$. These supports must be coated with intumescent material. Refer to standards (DTU P 06-002/003/006; NP EN 539-2; NP EN 539-1; NP EN 538; DTU.40.21 and 40.22; DTU 43.4-1) and to a ceramic tile application handbook for information in order to perform the various maintenance operations. 
Conditions of use operation: Avoid tying in unforeseen elements which may mean considerable overloads.

The analysis of the results leads to the conclusion that the decision support model defined enables the implications of each choice from among the solutions to be clarified, according to the various maintenance operations and their context, as well as the relationship of the different operational performance requirements with each operation; it also allows maintenance recommendations to be made for inclusion in the Maintenance Plan. Below is a summary of the model evaluation parameters [7]:

- Description of the composition of the constructive system element (structure, support, coating and finish) and its components and materials;

- Definition of the most likely anomalies associated with each element;

- Definition and description of existing and proposed solutions for each constructive system element;

- Definition of the set of operational performance requirements that the solution must meet and the relevant maintenance operations;

- Evaluation of the solutions for each element according to the maintenance importance of each action in order to ensure a given requirement and its conditions (specific criteria) through the lid and ease of maintenance through the Eid, for each action and for each constructive system element;

- Definition of the maintainability index (MI) for each operation according to an appraisal scale ]0;5[ by means of two charts: polygon and density, as shown in Figure 4.

From the results shown in Figure 4, it may be concluded by way of example that the solution analyzed for a given constructive system element is shown in terms of maintainability, i.e., an ability to respond to somewhat deficient maintenance operations, cleaning $(\mathrm{Cl})$ and replacement $(\mathrm{Rp})$. The model is not intended to create a hierarchy of solutions but only to raise awareness of the importance of maintenance within a given solution.

\section{Conclusions}

Emotions and understanding are rooted in the past. However, if one allows the design process to become repeatedly entangled in subjective and ill-conceived ideas, it may happen that personal feelings are given free rein in the design process [8]. As such, it is important that concrete aids be at hand to help the designer throughout the design process, without becoming an imposition on the act of creating and perceiving his or her surroundings.

The definition of a multicriteria decision support model contributes the systematization of the necessary maintenance information during the design process, which subsequently allows an initial Maintenance Plan to be established through a set of guidelines, to then become the updated Maintenance Plan; this, once the work is completed and the various solutions adopted are stabilized, will be integrated into the relevant Maintenance Manual.

The definition of a decision support tool in the preliminary design stages for the decision-maker/architect becomes instrumental as an integral tool of design practice, rather than something that is defined after the event. It is a clarifying input to design practice. Another aspect that the model intends to show is that it is possible to build and apply an evaluation methodology with a maintenance analysis component and to identify its implications.

It should be noted that we do not intend to preclude constructive solutions or quantify them, but rather classify the implications of their adoption in terms of the consequent maintenance needs [9]. In this way, a database for maintenance operations is created for the service life of the solution at issue, which allows the designer to guard against any future problems and has added value for all stakeholders in the construction process. 
Author Contributions: This study is the result of the research included in Patrícia Fernandes Rocha 's Ph.D. thesis and a grant supported by the Faculty of Engineering of University of Porto, and was supervised by the Rui Calejo Rodrigues, that provided critical judgment on the research being undertaken. The paper was written with the contribution of all authors.

Conflicts of Interest: The authors declare no conflict of interest.

\title{
Abbreviations
}

\author{
CSTC Centre Scientifique et Technique de la Construction \\ DSS decision support system \\ ESM element source of maintenance
}

\section{References}

1. British Standards Institute. Glossary of Maintenance Management Terms in Terotechnology; British Standards Institute: London, UK, 1984.

2. International Organization for Standardization. Buildings and Constructed Assets Service Life Planning ISO 15686-1: Parte 1 General Principles; ISO: Geneva, Switzerland, 2011.

3. Roders, A. Re-Architecture Lifespan Rehabilitation of Built Heritage. Ph.D. Thesis, Technische Universiteit Eindhoven, Eindhoven, The Netherlands, 2007.

4. Chamosa, J.V.; Ortiz, J.R. Patología de la construcción en España: Aproximación estadística. Inf. Constr. 1984, 36, 5-15.

5. Cnudde, M. Lack of quality in construction: Economic losses. In European Symposium on Management, Quality and Economics in Housing; UKE \& FN Spon: London, UK, 1991.

6. Anonymous. Gestão de Edificios. Modelo de Simulação Técnico-Económica. Ph.D. Thesis, Faculty of Engineering of Porto University, Porto, Portugal, 2001.

7. Anonymous. A Manutenção no Processo de Conceção Arquitetónica. Modelo de Apoio à Decisão. Ph.D. Thesis, Faculty of Engineering of Porto University, Porto, Portugal, 2014.

8. Zumthor, P. Pensar a Arquitectura; Editorial GG: Barcelona, Spain, 2009.

9. Arditti, D.; Nawakorawit, M. Designing buildings for maintenance: Designer's perspective. J. Archit. Eng. 1999, 5, 107-116. [CrossRef] 